\title{
Removal of Ethanethiol Gas by Iron Oxide Porous Ceramsite Biotrickling Filter
}

\author{
Peipei Wang, ${ }^{1,2}$ Shuchuan Peng, ${ }^{1,2}$ Chengzhu Zhu, ${ }^{1,2}$ Xiongjun Zhang, ${ }^{2}$ and Fei Teng \\ ${ }^{1}$ Jiangsu Key Laboratory of Atmospheric Environment Monitoring and Pollution Control, School of Environmental Science and \\ Engineering, Nanjing University of Information Science and Technology, Nanjing 210044, China \\ ${ }^{2}$ School of Resources \& Environmental Engineering, Hefei University of Technology, Hefei 230009, China
}

Correspondence should be addressed to Shuchuan Peng; scpeng@vip.sina.com and Fei Teng; tfwd@nuist.edu.cn

Received 22 September 2014; Accepted 16 December 2014

Academic Editor: Jian Lu

Copyright (C) 2015 Peipei Wang et al. This is an open access article distributed under the Creative Commons Attribution License, which permits unrestricted use, distribution, and reproduction in any medium, provided the original work is properly cited.

\begin{abstract}
The performance of ethanethiol removal in biotrickling filter was investigated by microorganisms fixed on iron oxide-based porous ceramsite (IPC) under different operating parameters conditions. Ethanethiol removal efficiency was examined as a function of inlet concentration, empty bed residence time (EBRT), and spray density of nutrient solution. The results showed that the optimized operation conditions and operation characteristics of biotrickling filter for this study were at the inlet concentration of less than $250 \mathrm{mg} \cdot \mathrm{m}^{-3}$, the spray density of $0.24 \mathrm{~m}^{3} \cdot \mathrm{m}^{-2} \mathrm{~h}^{-1}$, and the EBRT of $68.7 \mathrm{~s}$. The variation of the EBRT of about $100 \mathrm{~s}$ and the spray density of about $0.24 \mathrm{~m}^{3} \cdot \mathrm{m}^{-2} \mathrm{~h}^{-1}$ did not change the ethanethiol removal efficiencies at certain ethanethiol concentrations of less than about $300 \mathrm{mg} / \mathrm{m}^{3}$, respectively. The main metabolic product was sulfate such as $\mathrm{SO}_{4}{ }^{2-}$ under continuous long-running regime in filter. The ethanethiol desulfurization process better meets the Michaelis-Menien model with calculated kinetic degradation parameters $K_{s}=7.96 \mathrm{mg} \cdot \mathrm{m}^{-3}$ and $V_{m}=221.73 \mathrm{~g} \cdot \mathrm{m}^{-3} \mathrm{~h}^{-1}$.
\end{abstract}

\section{Introduction}

Ethanethiol $\left(\mathrm{ET}, \mathrm{CH}_{3}-\mathrm{CH}_{2}-\mathrm{SH}\right)$ is volatile organic sulfur compounds (VOSCs) with an intensive garlic odour; it is often used as malodorant and warning agent and is a significant organophosphorus pesticide intermediate $[1,2]$. ET is usually released from various industries and can cause different kinds of environmental problems. And when it functioned in the central nervous system of human body, it could cause poisoning, headache, and nausea and even lead to death due to respiratory paralysis [3]. Therefore, it is desirable and catches many people's growing concern to develop new technologies or improve existing treatment technologies to control such VOSCs like ET nowadays. Lots of physical and chemical abatement technologies, such as combustion method [4-6], oxidation process [7-9], and absorption method [10, 11], have been invented for purifying VOSCs. But their performance is not satisfying and they do not really degrade VOCs. By some traditional physical technologies, VOCs may just be transferred from gaseous phase to other phase [12]. Moreover, the chemical technologies are generally much more expensive [4]. However, the biological technologies have been reported by some research to be a promising effective alternative for desulfurization processes for removal of VOSCs with low operating costs, low operating requirements, and no by-products produced for disposal treatment moreover, they can process simultaneously two or more contaminants [13-16]. Biotrickling filter and biofiltration processes are two sorts of biological desulfurization process that have been widely applied [12, 14-18]. And compared with other biological methods, biotrickling filter process was proved to have an advantage of higher rates of mineralization $[12,19]$.

In recent years, the biological treatment study of VOCs such as ethanethiol could be mainly summarized about these respects, the research for advantage microbial strains cultivation and living conditions optimization, the designation and optimization of the biological reactor, as well as the biological filter, and the research for biodegradation dynamics. For example, An et al. [12, 19] had inoculated with Lysinibacillus sphaericus strain RG-1 or RG-1 and B350 mixed microorganisms in biotrickling filter columns to remove ethanethiol 
and single, binary, and ternary mixture gas of ethanethiol, dimethyl disulfide, and thioanisole. However, both researches had got satisfying results. And with the continuous development of anaerobic technology [20-22], Arellano-García et al. [23] had used an aerobic biotrickling filter system for removal of waste gas containing ethanethiol from their published paper. In addition, Sedighi and Vahabzadeh [24] studied the kinetic modeling of cometabolic degradation of ethanethiol. Hernández et al. [25] had used biotrickling filters packed with poplar wood and polyurethane foam to remove simultaneously $\mathrm{H}_{2} \mathrm{~S}, \mathrm{NH}_{3}$, and ET and investigate the impact of $\mathrm{pH}$ during startup and crossed effects evaluation.

In present study, biotrickling filter system was employed in this study for the purpose of removal of target gas, ethanethiol. Organic sulfide was absorbed by microorganism fixed on packing materials (usually Thiobacillus such as $T$. denitrificans, T. thioparus, and others) and then degraded and transformed to inorganic sulfate or elemental sulfur [26-30]. The effects of the filter performance with different operating parameters such as inlet concentration spray amount and empty bed residence time (EBRT) in the stage of start-up and stable-running were systematic investigated. In addition, dynamic analysis for this biological desulfurization process was also preliminarily discussed. All of the research contents would provide an effective technical reference for further study and application about biotrickling filter.

\section{Materials and Methods}

2.1. Experimental Set-Up and Technological Process. Using multilayer filler could improve the treatment efficiency and stability of filtration column because of the decreased relative thickness of each layer which would reduce the weight of filler of each layer and lead the filler difficultly to compact. While air flow was redistribute through each layer, so that the gas flow distribution could be more uniform, the flow rate could decrease and the residence time could be longer. Huaxin et al. [31] used natural corncob and sawdust as filter and divided the column into three layers to remove $\mathrm{H}_{2} \mathrm{~S}$; the results showed that, in the test inlet concentration, a multilayer filter had a slight advantage over a single layer filter for the removal of $\mathrm{H}_{2} \mathrm{~S}$. However, the stabilization and the removal efficiency of biofilters were also improved. Chen et al. [32] used three pilot-scale immobilized-cell biotrickling filters for removal of hydrogen sulfide from a contaminated air steam and got a good performance. In present study, the biotrickling filter was a self-made plexiglass column (Figure 1) divided into three layers with filter inner diameter of $90 \mathrm{~mm}$ and the total reactor height of $1200 \mathrm{~mm}$. Each layer was packed with $200 \mathrm{~mm}$ height iron oxide-based porous ceramsite (IPC) with particle size determined of about $5-8 \mathrm{~mm}$. And the mud content was about $0.27 \%$, hydrochloric acid soluble rate was approximately $0.43 \%$, porosity was $71.48 \%$, surface area was $7.1 \times 10^{5} \mathrm{~cm}^{2} \cdot \mathrm{g}^{-1}$, a bulk density was $0.46 \mathrm{~g} \cdot \mathrm{mL}^{-1}$, an apparent density was $1.71 \mathrm{~g} \cdot \mathrm{cm}^{-3}$, ceramic strength was about $51-78 \mathrm{~N}$, and porosity ratio was about $40.5-64.3 \%$. The biotrickling filter was employed with up-flow running mode, a countercurrent operation [33]. Ethanethiol gas entered from

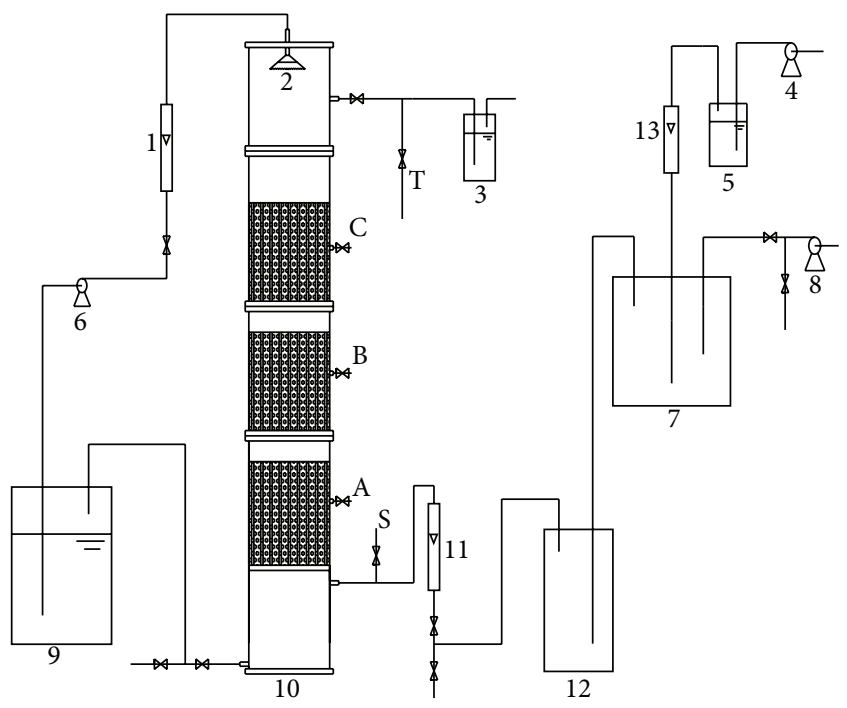

FIGURE 1: Biotrickling filter set-up and technological process (1: liquid-flow meter; 2 : sprinklers; 3: absorption bottle; 4: air pump; 5: ethanethiol reservoir; 6: peristaltic pump; 7: mixing gas tank; 8: compressor; 9: nutrient recirculation tank; 10: biotrickling filter; 11 and 13: gas-flow meter; 12: buffered gas-bottle; S, A, B, C, T: sampling port).

the bottom of the filter, through three IPC filler layers, and then outflew from the top. However, circulating nutrient solution was totally opposite, sprayed from the top to the bottom lifted to reservoir tank by water pump (BQ5Q1-1J peristaltic pump, Baoding Longer Pump). And in order to sample output gas there was a sampling port in each layer.

Certain concentration of ET was prepared by the method of dynamic preparation method. In other words, a small amount of air was bubbled into liquid ET solution in the ethanethiol reservoir to produce the pure ET gas, then the ET gas entered into mixing gas tank and mixed with air in order to form a certain concentration gas. Considered environmentally, the exhaust gas compound flew through the biotrickling filter was finally absorbed with $32 \% \mathrm{NaOH}$.

2.2. Analytical Methods. The concentrations of ET were analyzed by the amino dimethyl aniline spectrophotometry (GBZ/T160.49-2004) [34]. And the performance of studied biotrickling filter was generally evaluated by

$$
\operatorname{RE}(\%)=\frac{C_{\mathrm{in}}-C_{\mathrm{ot}}}{C_{\mathrm{in}}} \times 100,
$$

where $C_{\text {in }}\left(\mathrm{mg} \cdot \mathrm{L}^{-1}\right)$ is the inlet concentrations and $C_{\mathrm{ot}}$ $\left(\mathrm{mg} \cdot \mathrm{L}^{-1}\right)$ is the outlet concentrations of gas compounds. However, the various inlet loads $N_{v}\left(\mathrm{~g} \cdot \mathrm{m}^{-3} \mathrm{~h}^{-1}\right)$ calculated by (2) are also a significant parameter evaluating the filter performance:

$$
N_{v}=\frac{C_{\text {in }} \cdot Q}{1000 V},
$$

where $Q\left(\mathrm{~m}^{3} \cdot \mathrm{h}^{-1}\right)$ is gas volume flow of gas compounds of ET and $V\left(\mathrm{~m}^{3}\right)$ is the volume of studied biotrickling filter. 
In addition, empty bed residence time EBRT (s) and spray density $\rho\left(\mathrm{m}^{3} \cdot \mathrm{m}^{-2} \mathrm{~h}^{-1}\right)$ as two necessary parameters can calculated by

$$
\begin{gathered}
T=\frac{V}{Q} \cdot 3600, \\
\rho=\frac{4 Q_{l}}{\pi D^{2}},
\end{gathered}
$$

where $T$ (s) is EBRT and $Q$ and $V$ in (3) are same as defined above in (2); $Q_{l}\left(\mathrm{~m}^{3} \cdot \mathrm{h}^{-1}\right)$ and $D(\mathrm{~m})$ in (4) are liquid spray flow and inner diameter of filter, respectively.

The energy of microbial growth metabolism provided by only ethanethiol in the process of the biodegradation of ethanethiol occurred in studied filter [30]. Because of the biodegradation by microorganism, organic sulfate (ET) could be transformed to inorganic sulfate or elemental sulfur such as $\mathrm{SO}_{4}{ }^{2-}$, which led the nutrient solution change spontaneously into acidification. If ET can be completely degraded, the reaction is as follows [12]:

$$
\mathrm{C}_{2} \mathrm{H}_{5} \mathrm{SH}+5 \mathrm{O}_{2} \longrightarrow 2 \mathrm{CO}_{2}+2 \mathrm{H}_{2} \mathrm{O}+\mathrm{H}_{2} \mathrm{SO}_{4}
$$

In that case the concentration of $\mathrm{SO}_{4}{ }^{2-}$ was determined through spectrophotometric method (GB/T13025.8-91) [35]. The microbiological quality fixed on inorganic packing surface was observed by using Scanning Electron Microscope (SEM, XL30 ESEM-TMP).

\section{Results and Discussions}

3.1. Biotrickling Filter Start-Up and Running Performance. Biotrickling filter started and run at certain conditions in which the experimental temperature was $20^{\circ} \mathrm{C}-25^{\circ} \mathrm{C}$, the inlet concentration of ET was about $47.15-434.28 \mathrm{mg} \cdot \mathrm{m}^{-3}$, the spray density was about $0.08-0.31 \mathrm{~m}^{3} \cdot \mathrm{m}^{-2} \mathrm{~h}^{-1}$, and EBRT was $60 \mathrm{~s}$ after inoculating tame activated sludge (Zhu Zhuanjing sewage treatment plants of Hefei, Oxidation ditch). The performance of biological removal of ET was presented in Figure 2 after $26 \mathrm{~d}$.

Figure 2 showed that the ET removal efficiencies were $48.10 \%, 55.65 \%$, and $61.45 \%$ on the 1 st $\mathrm{d}, 4$ th $\mathrm{d}$, and 12 thd, respectively, with concentration of ET less than $251.24 \mathrm{mg} \cdot \mathrm{m}^{-3}$. The removal efficiency stabilized at around $60 \%$ after a 18 days' steady running of biotrickling filter with increased ET inlet concentration. However, 58.9\% removal efficiency was detected on 26th d. The biofilm biomass was also determined about $0.034 \mathrm{~g} \cdot \mathrm{g}^{-1}$. And a white membranous substance attached to packing materials was observed in filter by naked eye. It was also found that larger ellipsoid bacteria with dimensions of about $18 \times 38 \mu \mathrm{m}$ with scaly structure are present in packing materials surface. From the SEM results (Figures 3(a) and 3(b)), the scaly structure had a serrated opening at one end. In addition, the substances immobilized on the surface of IPC filler were scraped to be observed under the microscope; the photo is shown in Figures 3(c) and 3(d). The freedom movement of rod-shaped microorganism could be found obviously in the observation. In a word, biotrickling filter start-up of inoculated operation completed basically after $26 \mathrm{~d}$.

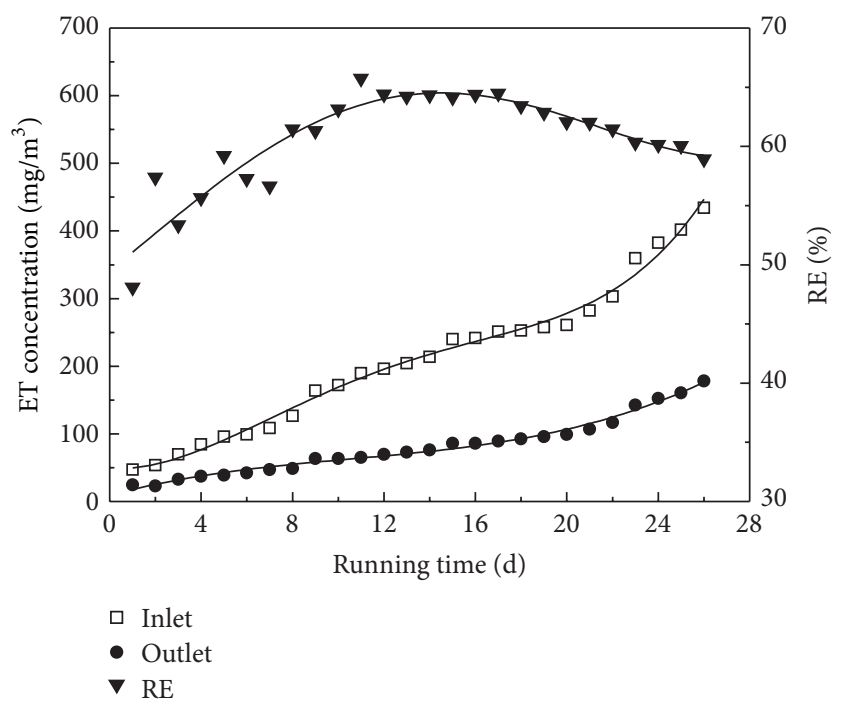

FIGURE 2: The ethanethiol inlet and outlet concentration and removal efficiency in start-up period.

3.2. Effect of Inlet Concentration on RE. In any biofiltration desulfurization process the initial concentration was a significant parameter on RE [27]. To study the effect of inlet concentration ranging from 100 to $500 \mathrm{mg} \cdot \mathrm{m}^{-3}$ on RE in filter, experiment operation condition was controlled at a temperature of about $20-25^{\circ} \mathrm{C}$, spray density of $0.24 \mathrm{~m}^{3} \cdot \mathrm{m}^{-2} \mathrm{~h}^{-1}$, and EBRT of 60 s. The results were shown in Figure 4. It can be seen that the RE of ET was reduced when the inlet concentration increased. 63.98\% RE obtained decreased into $57.39 \%$ when the inlet concentration increased from 95.74 to $501.39 \mathrm{mg} \cdot \mathrm{m}^{-3}$. While the inlet concentrations were less than $250 \mathrm{mg} \cdot \mathrm{m}^{-3}$, the removal efficiencies of ET were about $64 \%$ and the magnitude of decreasing of RE was smaller. In the study the maximum inlet load of the biotrickling filter was $34.22 \mathrm{~g} \cdot \mathrm{m}^{-3} \mathrm{~h}^{-1}$ and the actual maximum oxygen consumption was $88.30 \mathrm{~g}$ under the current biosystem according to the stoichiometric degradation reaction. However, the experiment condition of air in the biotrickling filter can provide more than $150 \mathrm{~g}$ oxygen. Thus, oxygen is sufficient for the microorganism to degrade ET in this biosystem. And a higher concentration gradient of ET could be produced by increasing inlet concentration, which would improve gaseous biofilm mass transfer rate from liquid phase to gas phase [12]. But the reason of decreased RE of ET in this study probably could be summarized as reaction substances constraints or diffusion limitation regime [26]. In addition, as the initial ethanethiol concentration increases, more time is needed to achieve the same RE because the lag phase of bacteria may be extended at higher concentrations of substrate [36]. However, biomass accumulation may be enhanced due to increase the gaseous compounds of ET inlet concentration with the various inlet loads $N_{v}$ changed from 3.76 to $19.72 \mathrm{~g} \cdot \mathrm{m}^{-3} \mathrm{~h}^{-1}$ in the process, so that the thickness of the biofilm could increase synchronously. As a result, the gas flow was obstructed because the porosity of packing materials reduced which led to decrease of biological activity [15]. 


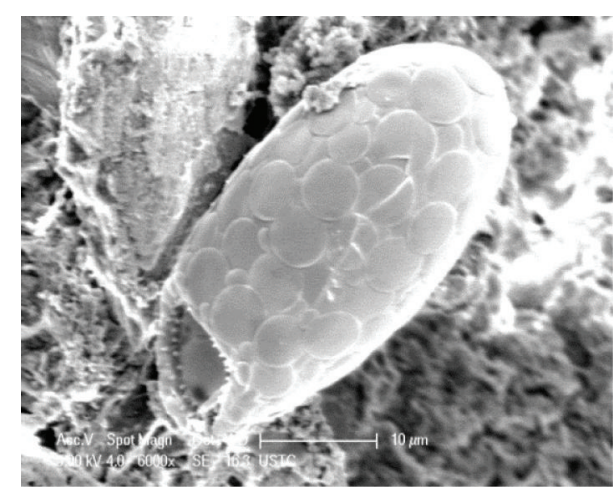

(a)

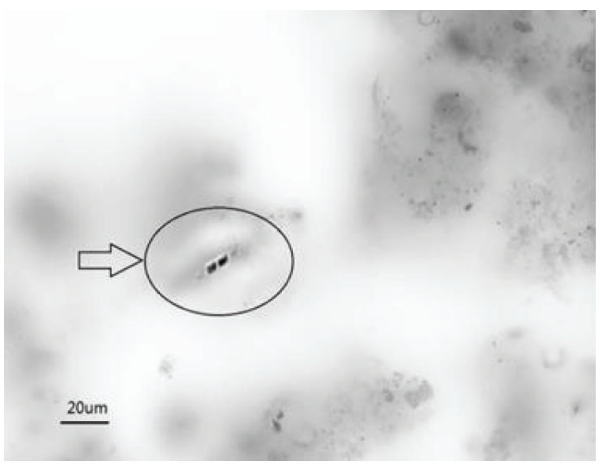

(c)

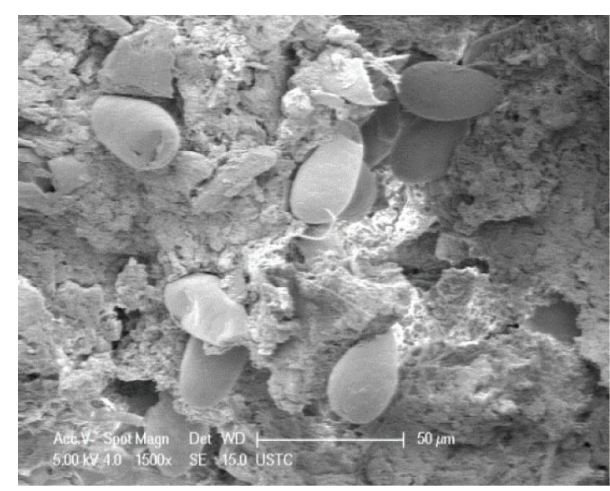

(b)

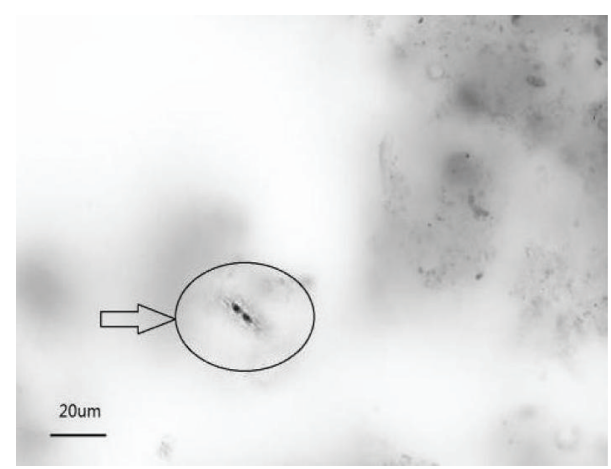

(d)

FIGURE 3: SEM images $(a, b)$ and microscope photo $(c, d)$ of IPC ceramsite after microbial inoculation.

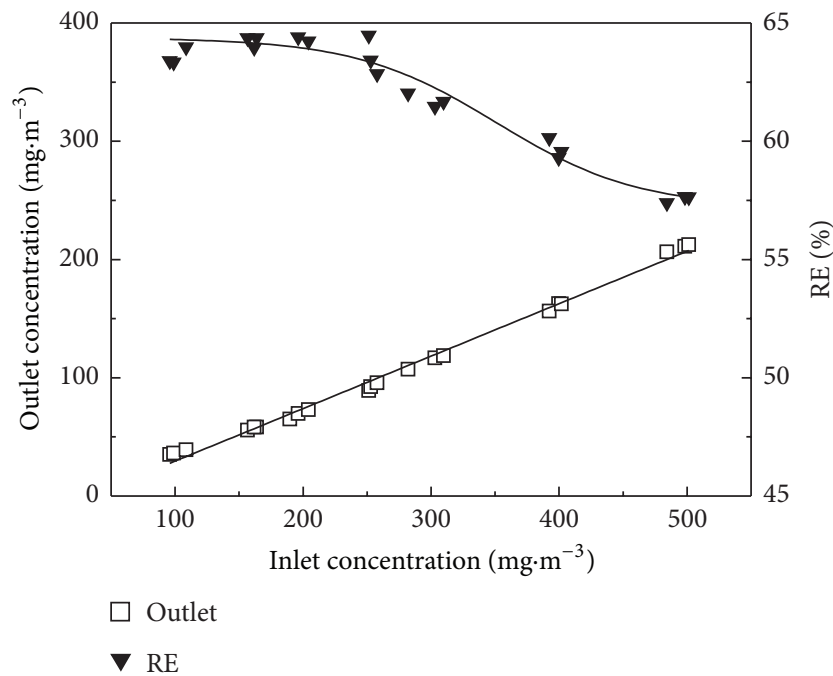

FIGURE 4: The effects of inlet concentration on ethanethiol removal efficiency.

3.3. Effect of EBRT on RE. EBRT was also a significant parameter of any biofiltration desulfurization process [12] and the effect of EBRT was studied at experimental condition where temperature was about $20-25^{\circ} \mathrm{C}$ and spray density was $0.24 \mathrm{~m}^{3} \cdot \mathrm{m}^{-2} \mathrm{~h}^{-1}$ in biotrickling filter (Figure 5). The results indicated that the removal performance could improve

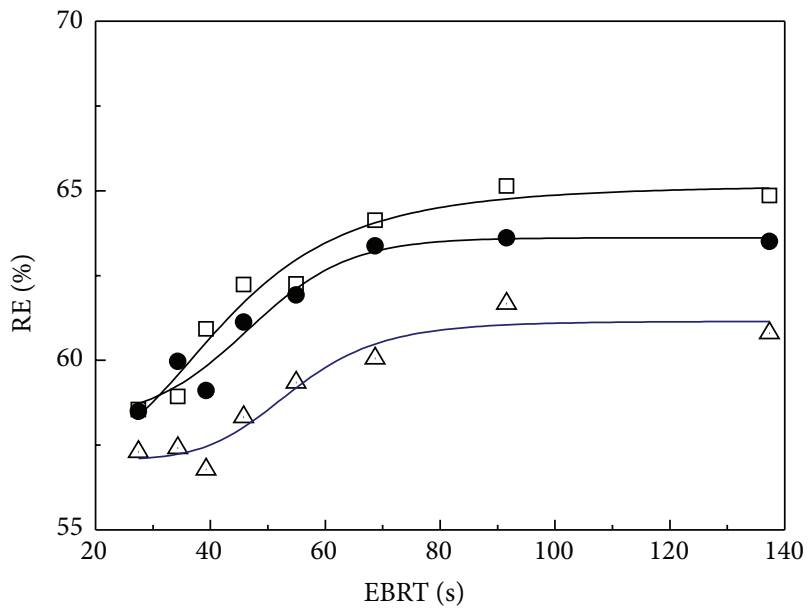

⒜ $200 \mathrm{mg} \cdot \mathrm{m}^{-3}$

- (b) $300 \mathrm{mg} \cdot \mathrm{m}^{-3}$

$\triangle$ (c) $400 \mathrm{mg} \cdot \mathrm{m}^{-3}$

FIGURE 5: The effects of EBRT on ethanethiol removal efficiency.

through increasing EBRT of biotrickling filter. Compared to three different inlet concentrations of effect of EBRT on RE, it could be seen a higher RE value when the ET inlet concentration was $200 \mathrm{mg} \cdot \mathrm{m}^{-3}$ or $300 \mathrm{mg} \cdot \mathrm{m}^{-3}$ than $400 \mathrm{mg} \cdot \mathrm{m}^{-3}$, and the RE value of group (a) and (b) was of similar at lower EBRT. When EBRT increased to about $70 \mathrm{~s}$ an obviously 
increased trend of RE was achieved with comparison value of three group, $200 \mathrm{mg} \cdot \mathrm{m}^{-3}>300 \mathrm{mg} \cdot \mathrm{m}^{-3}>400 \mathrm{mg} \cdot \mathrm{m}^{-3}$. In addition, better performance of RE was found at low concentration than high concentration of ET.

As 3.2 described, ET biological degradation reaction was mainly controlled by reaction substances constraints or diffusion limitation regime. The reason for higher RE values in longer EBRT condition was that the increased EBRT in the diffusion process which gas molecules transfer from gas phase to biofilm surface could provide sufficient time of this diffusion process to degrade contaminants by biological flora [12]. The diffusion of gas molecules restricted under shorter EBRT condition because the biofilm could not deal with excess gas molecules with enough react time that limited the total removal efficiency of filter [26]. And when EBRT added to a certain extent the changing curve trend of RE began to be smooth due to the limitation of microbial degradation [3]. Compared with the RE of three inlet concentrations $\left(200,300\right.$, and $\left.400 \mathrm{mg} \cdot \mathrm{m}^{-3}\right)$, group (a) and (b) showed higher performance than group (c) possibly due to the limitation of biological diffusion regime which may produce a exceed biomass accumulation. The results also indicated that a good performance of degrading ET achieved by employing biorickling filter, and about $70 \mathrm{~s}$ (superficial gas velocity of $8.74 \times$ $10^{-3} \mathrm{~m} \cdot \mathrm{s}^{-1}$ ) was the best EBRT for the biotrickling filter.

3.4. Effect of Spray Density on RE. The spray density was another key parameter in the biofiltration desulfurization process [37]. The effect of spray density on RE was investigated under experimental condition of which the temperature was $20-25^{\circ} \mathrm{C}$ and EBRT was $60 \mathrm{~s}$. There were also three groups studied under constant and variable gradient inlet concentration (shown in Figure 6). It could be seen that an upper trend of removal efficiencies in each group presented in Figure 6 was obtained with constantly increasing spray density. As Figure 6 shows, the ET REs of three groups (a), (b), and (c) had greatly improved when the spray density was less than $0.19 \mathrm{~m}^{3} \cdot \mathrm{m}^{-2} \mathrm{~h}^{-1}$; correspondingly, stable tendency of REs of three groups was achieved when the spray density was greater than $0.19 \mathrm{~m}^{3} \cdot \mathrm{m}^{-2} \mathrm{~h}^{-1}$ and the RE values were about $60 \%$.

Higher RE in biotrickling filter was found by increasing spray density probably mainly due to the metabolism of microorganisms [27-29]. The degradation process of ET through biological flora fixed on inorganic ceramic needs to obtain appropriate amount of nutrients from nutrient solution to maintain normal metabolism and growth of microorganisms [12]. So the amount of nutrients provided by nutrient solution became a limitation to the speed of metabolism of microorganisms. Thus increased spray density could stimulate the activity of microorganism metabolism because of the increase in the concentration of necessary nutrients [29]. When the spray density added up to a certain extent $\left(0.24 \mathrm{~m}^{3} \cdot \mathrm{m}^{-2} \mathrm{~h}^{-1}\right)$, the moisture content of packing materials surface would increase excessively and then resulted in a growth formation of liquid membrane on microbial membrane [27]. However, intemperate growth and excessive thick liquid membrane could affect the ET gas

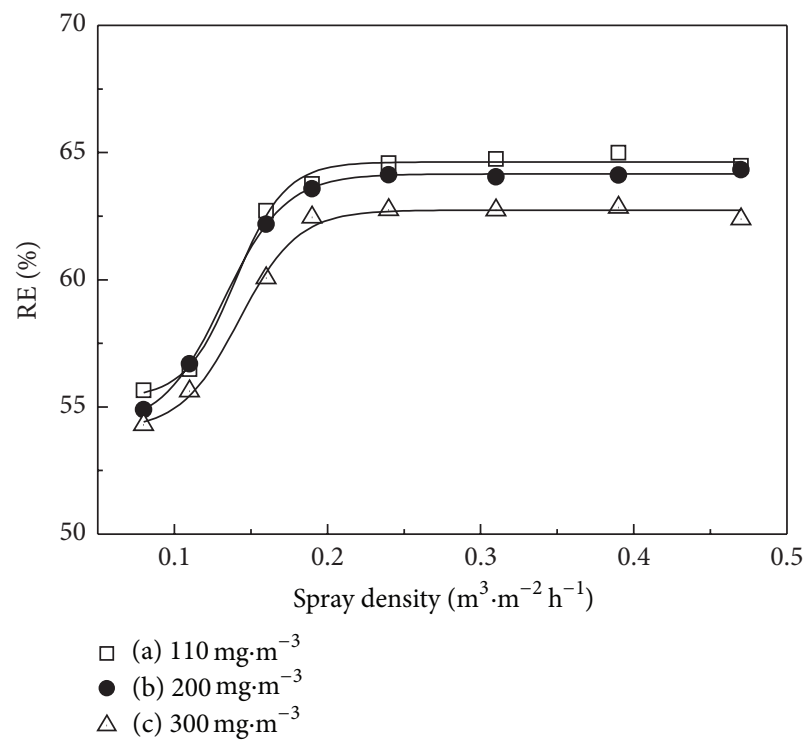

FIGURE 6: The effects of spray density on ethanethiol removal efficiency.

molecules inside diffusion with a result that microorganisms could not degrade ET successively or well. On the other hand, due to both reasons of nutrient limitation and hardly insoluble properties in water of ET (Henry coefficient: 0.15$0.21)$ [1], the RE increased extremely little even if the spray density was added, generally, the RE hardly increased. And the optimum spray density of nutrient solution in this study was $0.24 \mathrm{~m}^{3} \cdot \mathrm{m}^{-2} \mathrm{~h}^{-1}$.

3.5. Orthogonal Experiments. Three-factor and three-level orthogonal experiments were designed to decide the optimized condition of biotrickling filter. The main three investigated factors of orthogonal experiment were spray density $\left(0.08,0.24\right.$, and $\left.0.39 \mathrm{~m}^{3} \cdot \mathrm{m}^{-2} \mathrm{~h}^{-1}\right)$, EBRT $(34.34,68.67$, and $137.34 \mathrm{~s})$, and inlet concentration $\left(200,300\right.$, and $\left.400 \mathrm{mg} \cdot \mathrm{m}^{-3}\right)$. The experimental result was shown in Table 1. According to the range value of each factor, in present study situation, the affecting degree of each factor was spray density, inlet concentration, and EBRT. However, the optimized condition combined with previous experimental results could be determined as $0.24 \mathrm{~m}^{3} \cdot \mathrm{m}^{-2} \mathrm{~h}^{-1}$ of spray density, less than $250 \mathrm{mg} \cdot \mathrm{m}^{-3}$ of inlet concentration, and $68.7 \mathrm{~s}$ of the EBRT. However, the ethanethiol concentration after treatment by using the present biotrickling filter did not exceed $10.0 \mathrm{mg} \cdot \mathrm{L}^{-1}$ which was the maximum allowable concentration in an environment in regulations in this condition [2]. Thus, this study method was satisfying and was applied to remove low concentration of ethanethiol. Besides, according to research by Huaxin et al. [31], the bottom layer removed more than $50 \%$ of the target waste gas when the inlet concentration was lower than $70 \mathrm{mg} \cdot \mathrm{m}^{-3}$, but with the inlet concentration increasing to more than $90 \mathrm{mg} \cdot \mathrm{m}^{-3}$, the middle and upper layer played a major role for removal and the contribution of the bottom decreased to $35 \%$. Therefore, the higher RE could 
TABLE 1: The result of orthogonal experiments.

\begin{tabular}{|c|c|c|c|c|c|}
\hline Factor & Spray density $\left(\mathrm{m}^{3} \cdot \mathrm{m}^{-2} \mathrm{~h}^{-1}\right)$ & EBRT (s) & Inlet concentration $\left(\mathrm{mg} \cdot \mathrm{m}^{-3}\right)$ & Outlet concentration $\left(\mathrm{mg} \cdot \mathrm{m}^{-3}\right)$ & $\mathrm{RE}(\%)$ \\
\hline 1 & 0.08 & 34.34 & 200 & 86.62 & 56.69 \\
\hline 2 & 0.08 & 68.67 & 300 & 133.14 & 55.62 \\
\hline 3 & 0.08 & 137.34 & 400 & 182.08 & 54.48 \\
\hline 4 & 0.24 & 34.34 & 300 & 113.91 & 62.03 \\
\hline 5 & 0.24 & 68.67 & 400 & 159.88 & 60.03 \\
\hline 6 & 0.24 & 137.34 & 200 & 71.78 & 64.11 \\
\hline 7 & 0.39 & 34.34 & 400 & 159.81 & 60.05 \\
\hline 8 & 0.39 & 68.67 & 200 & 71.74 & 64.13 \\
\hline 9 & 0.39 & 137.34 & 300 & 109.89 & 63.37 \\
\hline Average 1 & 55.60 & 59.59 & 61.64 & & \\
\hline Average 2 & 62.06 & 59.93 & 60.34 & & \\
\hline Average 3 & 62.52 & 60.65 & 58.19 & & \\
\hline Range & 6.92 & 1.06 & 3.45 & & \\
\hline
\end{tabular}

probably reach more than $66 \%$ by using multilayer filler with more than three layers.

3.6. pH Values and Metabolic Product Analysis. Because no biotransformation exists to consume sulfate which was the major metabolic products [30] of ET in biotrickling filter, it would accumulate in the nutrient solution and the $\mathrm{pH}$ would drop with an increase in operation time. The $\mathrm{pH}$ values and sulfate concentrations of nutrient solution for ET removal were regularly determined in biotrickling filter during 34 -week operation period. And the results were shown in Figure 7.

As Figure 7(a) shows, there was a linear relationship between ET various inlet loads $N_{v}$ and sulfate concentration and $\mathrm{pH}$ values of nutrient solution. When the ET various inlet loads $N_{v}\left(\mathrm{~g} \cdot \mathrm{m}^{-3} \mathrm{~h}^{-1}\right)$ added from 7.39 to $11.34 \mathrm{~g} \cdot \mathrm{m}^{-3} \mathrm{~h}^{-1}$, the sulfate concentration ranged from 15.36 to $417.63 \mathrm{mg} \cdot \mathrm{L}^{-1}$, and $\mathrm{pH}$ values of nutrient solution dropped from 7.7 to 4.9 . Thus sulfate $\mathrm{SO}_{4}{ }^{2-}$ produced in the biofiltration desulfurization process was certain. After the values of $\mathrm{pH}$ added up to 5, there was no obvious change of trend of $\mathrm{SO}_{4}{ }^{2-}$ concentration even though various inlet loads $N_{v}$ added. That probably due to the weak alkaline ion besides $\mathrm{SO}_{4}{ }^{2-}$ such as $\mathrm{S}^{2-}$ and $\mathrm{SO}_{3}{ }^{2-}$ produced in desulfurization process [3]. There were some pale yellow substances with some characteristics of elemental sulfur material produced in the reactor, which makes the function of spray liquid did not further acidification [37]. In addition, the added concentrations of $\mathrm{SO}_{4}{ }^{2-}$ did not make a difference with $\mathrm{pH}$ values decreasing, indicating that the variation of $\mathrm{pH}$ nearly had no effect on the microbial degradation of ET in biotrickling filter.

Figure 7(b) was shown the relationship between removal efficiencies of ET and conversion of $\mathrm{SO}_{4}{ }^{2-}$ during the operation period. The conversion rates of $\mathrm{SO}_{4}{ }^{2-}$ showed lower trend at first with the maximum value of $99.62 \mathrm{mg} \cdot \mathrm{d}^{-1}$ and the minimum value of $64.22 \mathrm{mg} \cdot \mathrm{d}^{-1}$ under continuous operation in biotrickling filter reactor, and then there was a slight rise about $70-80 \mathrm{mg} \cdot \mathrm{d}^{-1}$. Therefore the conversion rate could keep at a high level for a longtime-running regime in the bioreactor. An unobvious drop magnitude of ET removal efficiency from $64.98 \%$ to $62.30 \%$ could be also seen.

3.7. Kinetic Analysis. Biotrickling filter reactor was a kind of nonsubmerged gas phase bioreactor [38]. Based on the research hypothesis that the microorganism fixed on inorganic packing surface distributes evenly, the airstream mode was plug-flow and oxygen condition was not a limitation for biological aerobic respiration, consult relevant information literature $[38,39]$, Michaelis-Menien equation was an appropriate biological degradation mode for this studied desulfurization process:

$$
R_{s}=\frac{V_{m} \cdot C}{K_{s}+C},
$$

where $R_{s}\left(\mathrm{~g} \cdot \mathrm{m}^{-3} \mathrm{~d}^{-1}\right)$ is substrate utilization rates, $V_{m}$ $\left(\mathrm{g} \cdot \mathrm{m}^{-3} \mathrm{~d}^{-1}\right)$ is the maxim removal rates, and $C\left(\mathrm{mg} \cdot \mathrm{m}^{-3}\right)$ is concentration of contaminant and $K_{s}$ is half-saturation constant in equation. A simplified equation (7) obtains by linearizing the equation of Michaelis-Menien Mode through Lineweaver-Burk:

$$
\frac{1}{R}=\frac{K_{s}}{V_{m} \cdot C_{\ln }}+\frac{1}{V_{m}},
$$

where $R$ is removal rates of contaminant $\left[Q\left(C_{\text {in }}-C_{\text {ot }}\right) / V\right]$ and $C_{\ln }$ is log-average concentration of contaminant $\left[\left(C_{\text {in }}-\right.\right.$ $\left.\left.C_{\mathrm{ot}}\right) / \ln \left(C_{\mathrm{in}} / C_{\mathrm{ot}}\right)\right]$. In addition, $C_{\mathrm{in}}\left(\mathrm{mg} \cdot \mathrm{L}^{-1}\right)$ and $C_{\mathrm{ot}}\left(\mathrm{mg} \cdot \mathrm{L}^{-1}\right)$ are the inlet concentrations and the outlet concentrations of gas compounds, respectively. $Q\left(\mathrm{~m}^{3} \cdot \mathrm{h}^{-1}\right)$ is gas volume flow of gas compounds of ET. There the intercept and slope could be calculated from a linear relationship between $1 / R$ and $1 / C_{\ln }$ by analyzing experimental data because they do represent $K_{s}$ and $V_{m}$.

The experimental data of ET outlet concentration during constantly stable long-running regime in biotrickling filter system had been fitted with Michaelis-Menien model [39]. And the running conditions were at a temperature of $25^{\circ} \mathrm{C}$, inlet gas flow of about $0.15 \mathrm{~m}^{3} \cdot \mathrm{h}^{-1}$, and the filter volume of 


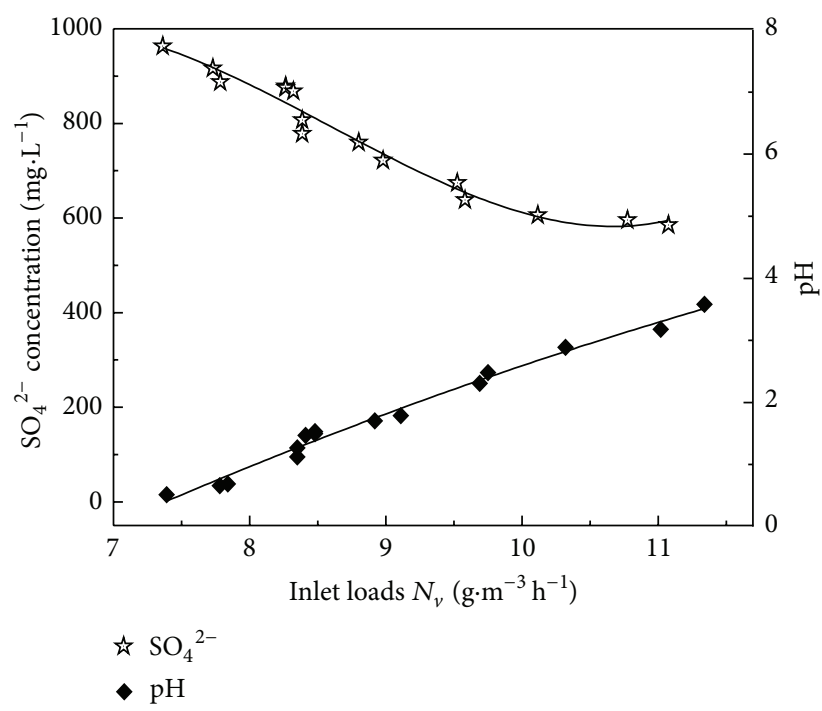

(a)

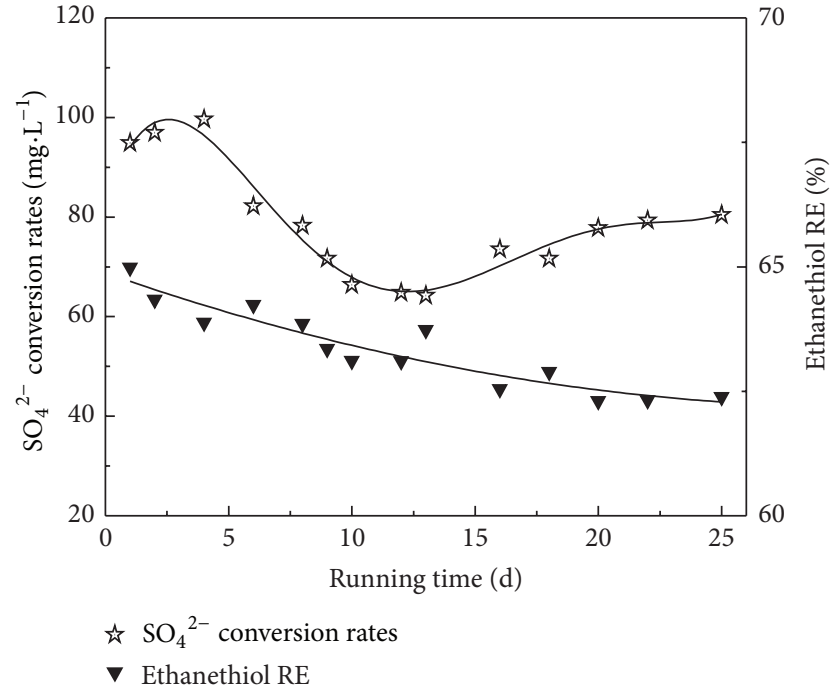

(b)

Figure 7: (a) The effects of ethanethiol inlet loads on sulfate ion concentration and $\mathrm{pH}$ and (b) continuous operation $\mathrm{SO}_{4}{ }^{2-}$ conversion rate and ethyl mercaptan removal rate.

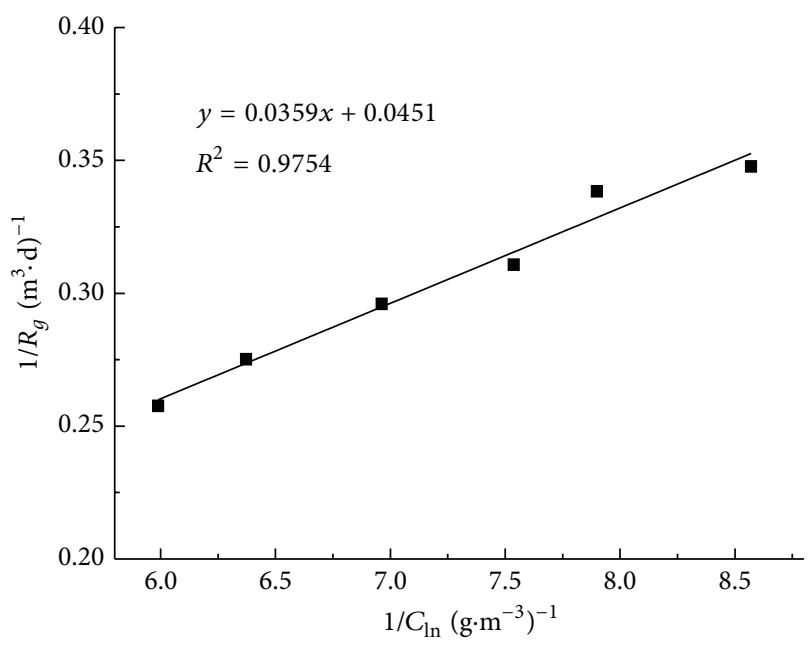

FIGURE 8: Fitting result of biotrickling filter system for ethanethiol removal.

$6.36 \times 10^{-3} \mathrm{~m}^{3}$. The fitted result was shown in Figure 8. The results showed that it could better meet the Michaelis-Menien models by using biotrickling filter for the removal of ET. The correlation coefficient $R^{2}$ was 0.975 that indicated a good correlation. Two kinetic parameters could be calculated as $K_{s}=7.96 \mathrm{mg} \mathrm{m}{ }^{-3}$ and $V_{m}=221.73 \mathrm{~g} \cdot \mathrm{m}^{-3} \mathrm{~h}^{-1}$.

\section{Conclusions}

The desulfurization process of sulfur odor ET by microorganisms fixed on iron oxide-based porous ceramsite (IPC) in biotrickling filter was investigated. The results showed that the optimum running conditions of ET degradation were at the inlet concentration of less than $250 \mathrm{mg} \cdot \mathrm{m}^{-3}$, the spray density of $0.24 \mathrm{~m}^{3} \cdot \mathrm{m}^{-2} \mathrm{~h}^{-1}$, and the EBRT of $68.7 \mathrm{~s}$. And more than $64 \%$ of ET removal efficiency was achieved in that case. In addition, the main metabolic product was $\mathrm{SO}_{4}{ }^{2-}$ under continuous long-running regime in filter, and the concentration of $\mathrm{SO}_{4}{ }^{2-}$ increased with $\mathrm{pH}$ dropping due to the increase of inlet loads. But both ranges of $\mathrm{SO}_{4}{ }^{2-}$ and $\mathrm{pH}$ had no significant effect on ET removal performance. The fitted experimental correlation coefficient $R^{2}=0.975$, and the kinetic degradation parameters $K_{s}=7.96 \mathrm{mg} \cdot \mathrm{m}^{-3}$ and $V_{m}=221.73 \mathrm{~g} \cdot \mathrm{m}^{-3} \mathrm{~h}^{-1}$. The ET desulfurization process could better meet with the Michaelis-Menien model.

\section{Conflict of Interests}

The authors declare that there is no conflict of interests regarding the publication of this paper.

\section{Acknowledgments}

The authors thank the financial support from Jiangsu Key Laboratory of Atmospheric Environment Monitoring and Pollution Control of Nanjing University of Information Science and Technology, Jiangsu Province Innovation Platform for Superiority Subject of Environmental Science and Engineering (no. KHK1203), and the Science and Technology Project of Anhui Province of China (no. 12010402097) for supporting this study.

\section{References}

[1] Y. Y. Li and L. X. Shi, "Comparison of GC-FPD and GC-FID in determining ethanethiol in air of workplace," Chinese Journal of Health Laboratory Technology, vol. 23, no. 16, pp. 3190-3228, 2013. 
[2] M. Sedighi, F. Vahabzadeh, S. M. Zamir, and A. Naderifar, "Ethanethiol degradation by Ralstonia eutropha," Biotechnology and Bioprocess Engineering, vol. 18, no. 4, pp. 827-833, 2013.

[3] A. M. Montebello, M. Fernández, F. Almenglo et al., "Simultaneous methylmercaptan and hydrogen sulfide removal in the desulfurization of biogas in aerobic and anoxic biotrickling filters," Chemical Engineering Journal, vol. 200-202, pp. 237246, 2012.

[4] E. Smet, P. Lens, and H. van Langenhove, "Treatment of waste gases contaminated with odorous sulfur compounds," Critical Reviews in Environmental Science and Technology, vol. 28, no. 1, pp. 89-117, 1998.

[5] K. Okada, T. Yamamoto, K.-H. Kim et al., "Removal of hydrogen sulfide with steelmaking slag by concurrent reactions of sulfide mineralization and oxidation," Ecological Engineering, vol. 63, no. 1, pp. 122-126, 2014.

[6] G. Muthuraman and M. Il-Shik, "Single catalyst of aqueous Co ${ }^{\text {III }}$ for deodorization of mixture odor gases: a development and reaction pathway study at electro- scrubbing process," Journal of Hazardous Materials, vol. 260, no. 1, pp. 1064-1072, 2013.

[7] S. Y. Yang, L. L. Wang, L. Y. Feng et al., "Wet scrubbing process for methyl mercaptan odor treatment with peroxides: comparison of hydrogen peroxide, perulfate and peroxymonosulfate," Environmental Chemistry, vol. 33, no. 1, pp. 81-86, 2014.

[8] D. C. Ding, G. Lu, P. Liu et al., "Photolysis and oxidation of hydrogen sulfide gas using high-intensity UV spherical lamp," Chinese Journal of Environmental Engineering, vol. 6, no. 12, pp. 4609-4614, 2012.

[9] A. S. Stasinakis, "Use of selected advanced oxidation processes (AOPs) for wastewater treatment: a mini review," Global Nest Journal, vol. 10, no. 3, pp. 376-385, 2008.

[10] G. Busca and C. Pistarino, "Technologies for the abatement of sulphide compounds from gaseous streams: a comparative overview," Journal of Loss Prevention in the Process Industries, vol. 16, no. 5, pp. 363-371, 2003.

[11] A. L. Cazetta, A. M. M. Vargas, E. M. Nogami et al., "NaOHactivated carbon of high surface area produced from coconut shell: kinetics and equilibrium studies from the methylene blue adsorption," Chemical Engineering Journal, vol. 174, no. 1, pp. 117-125, 2011.

[12] T. C. An, S. G. Wan, G. Y. Li, L. Sun, and B. Guo, "Comparison of the removal of ethanethiol in twin-biotrickling filters inoculated with strain RG-1 and B350 mixed microorganisms," Journal of Hazardous Materials, vol. 183, no. 1-3, pp. 372-380, 2010.

[13] X.-Q. Yang and B.-X. Tang, "Research and application status of biological deodorization technology," Modern Agricultural Science and Technology, vol. 6, no. 1, pp. 297-298, 2006.

[14] H. H. J. Cox and M. A. Deshusses, "Co-treatment of $\mathrm{H}_{2} \mathrm{~S}$ and toluene in a biotrickling filter," Chemical Engineering Journal, vol. 87, no. 1, pp. 101-110, 2002.

[15] Y. Jin, M. C. Veiga, and C. Kennes, "Co-treatment of hydrogen sulfide and methanol in a single-stage biotrickling filter under acidic conditions," Chemosphere, vol. 68, no. 6, pp. 1186-1193, 2007.

[16] Z. G. Xie, W. J. Guan, F. G. Ji, Z. Song, and Y. Zhao, "Production of biologically activated carbon from orange peel and landfill leachate subsequent treatment technology," Journal of Chemistry, vol. 2014, Article ID 491912, 9 pages, 2014.

[17] C. Hort, S. Gracy, V. Platel, and L. Moynault, "Evaluation of sewage sludge and yard waste compost as a biofilter media for the removal of ammonia and volatile organic sulfur compounds (VOSCs)," Chemical Engineering Journal, vol. 152, no. 1, pp. 44$53,2009$.

[18] B. Sercu, D. Núñez, G. Aroca, N. Boon, W. Verstraete, and H. van Langenhove, "Inoculation and start-up of a biotricking filter removing dimethyl sulfide," Chemical Engineering Journal, vol. 113, no. 2-3, pp. 127-134, 2005.

[19] S. Wan, G. Li, T. An, and B. Guo, "Co-treatment of single, binary and ternary mixture gas of ethanethiol, dimethyl disulfide and thioanisole in a biotrickling filter seeded with Lysinibacillus sphaericus RG-1," Journal of Hazardous Materials, vol. 186, no. 2-3, pp. 1050-1057, 2011.

[20] W.-B. Yang, W.-H. Chen, C.-S. Yuan, J.-C. Yang, and Q.-L. Zhao, "Comparative assessments of VOC emission rates and associated health risks from wastewater treatment processes," Journal of Environmental Monitoring, vol. 14, no. 9, pp. 24642474, 2012.

[21] Z.-B. Yue, H.-Q. Yu, H. Harada, and Y.-Y. Li, "Optimization of anaerobic acidogenesis of an aquatic plant, Canna indica L., by rumen cultures," Water Research, vol. 41, no. 11, pp. 2361-2370, 2007.

[22] J. W. van Groenestijn and N. J. R. Kraakman, "Recent developments in biological waste gas purification in Europe," Chemical Engineering Journal, vol. 113, no. 2-3, pp. 85-91, 2005.

[23] L. Arellano-García, A. González-Sánchez, G. Baquerizo, S. Hernández-Jiménez, and S. Revah, "Treatment of carbon disulfide and ethanethiol vapors in alkaline biotrickling filters using an alkaliphilic sulfo-oxidizing bacterial consortium," Journal of Chemical Technology and Biotechnology, vol. 85, no. 3, pp. 328335, 2010.

[24] M. Sedighi and F. Vahabzadeh, "Kinetic Modeling of cometabolic degradation of ethanethiol and phenol by Ralstonia eutropha," Biotechnology and Bioprocess Engineering, vol. 19, no. 2, pp. 239-249, 2014.

[25] J. Hernández, J. Lafuente, Ó. J. Prado, and D. Gabriel, “Simultaneous removal of $\mathrm{H}_{2} \mathrm{~S}, \mathrm{NH}_{3}$, and ethyl mercaptan in biotrickling filters packed with poplar wood and polyurethane foam: impact of $\mathrm{pH}$ during startup and crossed effects evaluation," Water, Air, \& Soil Pollution, vol. 223, no. 6, pp. 3485-3497, 2012.

[26] Y. Jin, M. C. Veiga, and C. Kennes, "Effects of $\mathrm{pH}, \mathrm{CO}_{2}$, and flow pattern on the autotrophic degradation of hydrogen sulfide in a biotrickling filter," Biotechnology and Bioengineering, vol. 92, no. 4, pp. 462-471, 2005.

[27] S. H. Li, B. Yan, F. Li et al., "Study on removal rate of methyl ercapatan and ethanethoil by bio-trickling filter," Journal of Natural Science of Heilongjiang Unversity, vol. 6, no. 22, pp. 724728, 2005.

[28] X. Y. Dong, Y. Zhao, and W. Kou, "Optimal operating conditions for $\mathrm{H}_{2} \mathrm{~S}$ removal by an anoxic bio-trickling reactor," Chinese Journal of Environmental Engineering, vol. 7, no. 6, pp. 23732377, 2012.

[29] J. Li, G. Ye, D. Sun, T. An, G. Sun, and S. Liang, "Performance of a biotrickling filter in the removal of waste gases containing low concentrations of mixed VOCs from a paint and coating plant," Biodegradation, vol. 23, no. 1, pp. 177-187, 2012.

[30] B. Liu, A.-X. Jiang, Y.-X. Cheng, Z. Li, and B.-Q. Li, "Removal of mixed $\mathrm{H}_{2} \mathrm{~S}-\mathrm{MT}$ stench by trickled-bed biofilters connected in series," China Environmental Science, vol. 23, no. 6, pp. 618-621, 2003.

[31] Z. Huaxin, L. Shunyi, Y. Songbo et al., "Research on treatment of odor gas containing hydrogen sulfide by multilayer biofilter," 
Chinese Journal of Environmental Engineering, vol. 5, no. 1, pp. 157-160, 2011.

[32] Y. Q. Chen, Z. D. Fan, L. X. Ma, J. Yin, M. Luo, and W. F. Cai, "Performance of three pilot-scale immobilized-cell biotrickling filters for removal of hydrogen sulfide from a contaminated air steam," Saudi Journal of Biological Sciences, vol. 21, no. 5, pp. 450-456, 2014.

[33] M. T. Namini, N. Abdehagh, S. M. Heydarian, B. Bonakdarpour, and D. Z. B. Kooki, "Hydrogen sulfide removal performance of a bio-trickling filter employing Thiobacillus thiparus immobilized on polyurethane foam under various starvation regimes," Biotechnology and Bioprocess Engineering, vol. 17, no. 6, pp. 12781283, 2012.

[34] The Minister of Health of the People's Republic of China, GBZ/T160.49-2004 Methods for Determination of Mercaptans in the Air of Workplace, Standards Press of China, Peking, China, 2004.

[35] The Minister of Health of the People's Republic of China, GB/T13025.8-91 General Test Methods in Salt Industry: Determination of Sulfate Ion, Standards Press of China, Beijing, China, 2004.

[36] S. Rappert and R. Müller, "Odor compounds in waste gas emissions from agricultural operations and food industries," Waste Management, vol. 25, no. 9, pp. 887-907, 2005.

[37] S. Kim and M. A. Deshusses, "Understanding the limits of $\mathrm{H}_{2} \mathrm{~S}$ degrading biotrickling filters using a differential biotrickling filter," Chemical Engineering Journal, vol. 113, no. 2-3, pp. 119126, 2005.

[38] H. X. Zhan, S. Y. Li, S. B. Yang et al., "Research on treatment of odor gas containing hydrogen sulfide by multilayer biofilter," Chinese Journal of Environmental Engineering, vol. 1, no. 5, pp. 157-160, 2011.

[39] Y. Lu, J. Liu, B.-N. Lu, F. Li, and A.-X. Jiang, "Process performance and kinetics of benzene and toluene waste-gas treatment by biological method," Chemical Engineering, vol. 7, no. 36, pp. 55-57, 2008. 

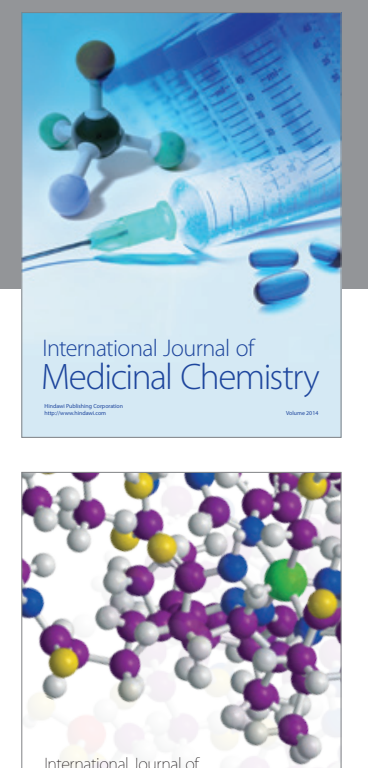

\section{Carbohydrate} Chemistry

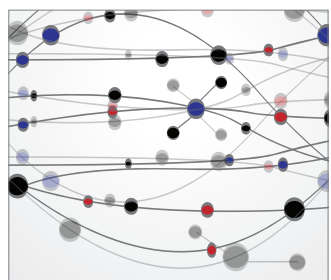

The Scientific World Journal
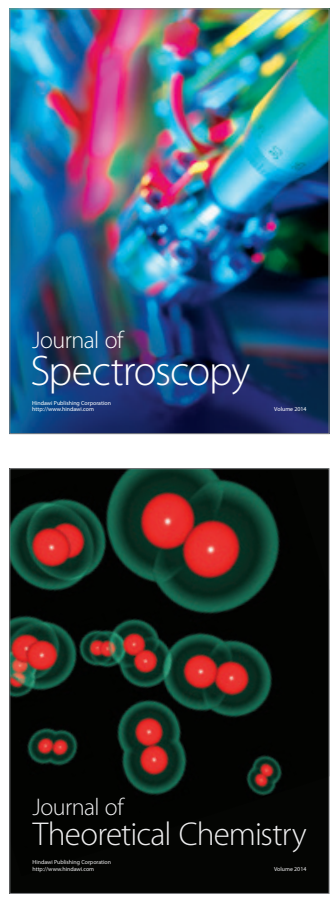
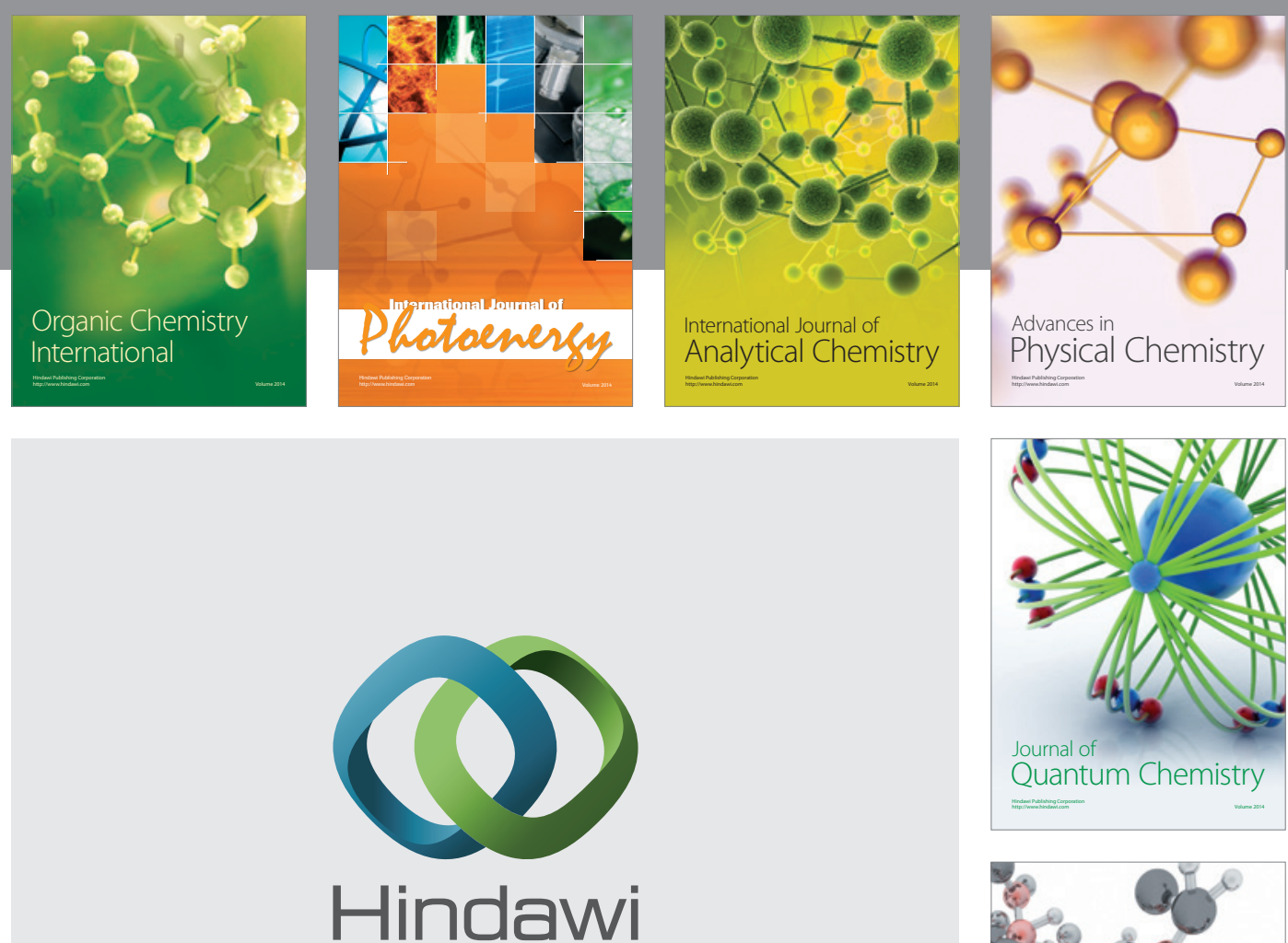

Submit your manuscripts at

http://www.hindawi.com

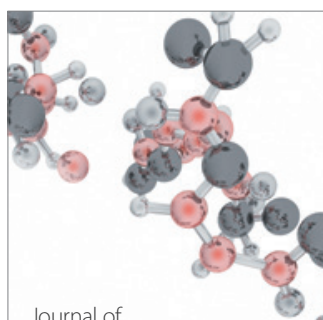

Analytical Methods

in Chemistry

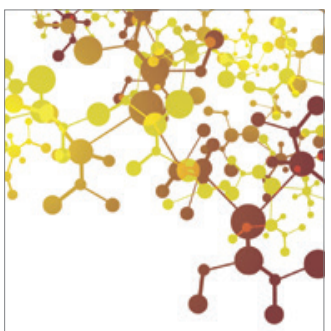

Journal of

Applied Chemistry

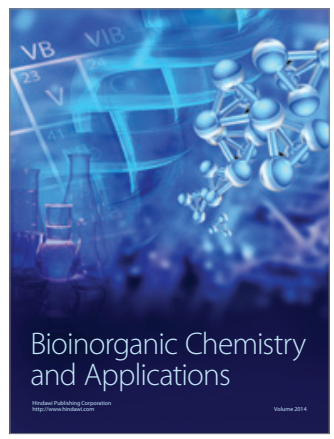

Inorganic Chemistry
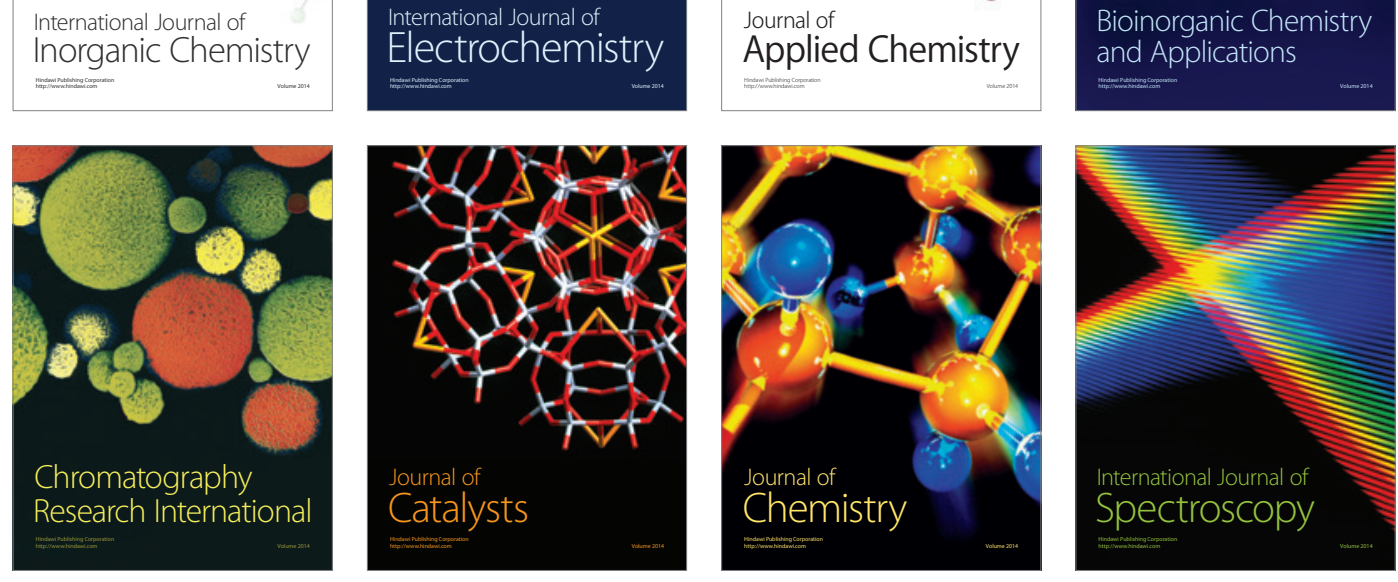